Document downloaded from:

http://hdl.handle.net/10251/127483

This paper must be cited as:

Alba, J.; Arenas, JP.; Rey Tormos, RMD.; Rodríguez-Vercher, J. (2019). An electroacoustic method for measuring airflow resistivity of porous sound-absorbing materials. Applied Acoustics. 150:132-137. https://doi.org/10.1016/j.apacoust.2019.02.009

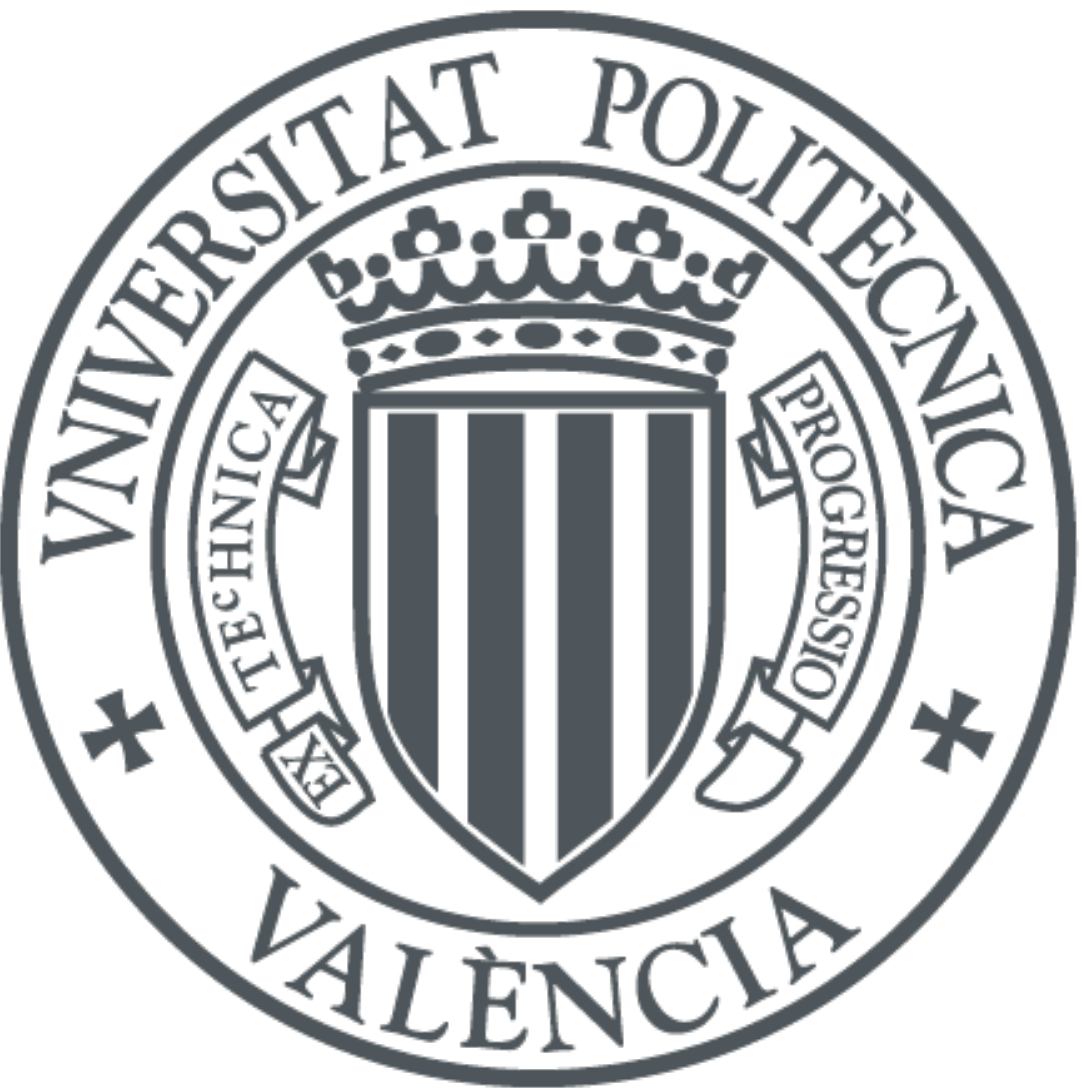

The final publication is available at

http://doi.org/10.1016/j.apacoust.2019.02.009

Copyright Elsevier

Additional Information 


\title{
An electroacoustic method for measuring airflow resistivity of porous sound-absorbing materials
}

\author{
Jesús Alba ${ }^{\mathrm{a}}$, Jorge P. Arenas ${ }^{\mathrm{b}, *}$, Romina del Rey ${ }^{\mathrm{a}}$, Juan C. Rodríguez ${ }^{\mathrm{a}}$ \\ ${ }^{a}$ Univ. Politècnica de València, Campus de Gandia, C/Paraninfo 1, 46730 Grao de Gandia, \\ Valencia, Spain \\ ${ }^{b}$ Institute of Acoustics, Univ. Austral of Chile, PO Box 567, Valdivia, Chile
}

\begin{abstract}
In this paper, a method for measuring the airflow resistivity of air-saturated porous sound-absorbing materials is presented. The method is based on a modification of the previous device developed by Dragonetti et al. The approach used in the present work involves a cavity and a Helmholtz resonator that are coupled through a loudspeaker so that the complete system behaves as a fourth-order symmetrical band-pass loudspeaker system. After a straightforward calibration, the airflow resistivity of a material sample is indirectly estimated from the direct measurement of the total electric impedance at the loudspeaker connection terminals. In this way, the use of microphones is not necessary, which makes its implementation very simple and inexpensive. Experimental results obtained with the present method agree well with those obtained through a standardized method as long as the values of the material's airflow resistance are not too high.

Keywords: airflow resistivity, impedance, porous materials, sound absorption, electroacoustics
\end{abstract}

PACS: 43.58.Bh, 43.58. Vb

*Corresponding author, Tel.: +56-63-2221012; fax: +56-63-2221013

Email address: jparenas@uach.cl (Jorge P. Arenas) 


\section{Introduction}

Airflow resistivity is one of the main nonacoustic parameters used to characterize the sound absorption properties of a porous material. It is defined as the airflow resistance (i.e., the ratio of the pressure drop across a material sample to the volumetric air flowing through it) per unit material thickness. The airflow resistivity is also a property required in most equivalent fluid theoretical models for porous materials $[1,2]$. Thus, because this property is directly related to the capacity of a material to absorb sound energy, airflow resistivity is also used in practice for selecting appropriate materials for noise control and architectural acoustics applications.

Measurement of airflow resistivity has also been a subject of great interest in the field of technical textiles. Specific methods have been reported for woven and nonwoven textiles having high airflow resistivity but very low thickness, such as that of Jaouen and Bécot [3]. Other authors have presented formulas based on electrical circuit models for its prediction in thin textiles [4]. A more recent study on the prediction of sound absorption coefficient of textiles based on the airflow resistivity has been published by Tang et al. [5].

Several organizations, including ISO and ASTM, have described the standardized laboratory procedures for measuring airflow resistivity [6,7]. A procedure described by ISO and ASTM is based on a steady laminar flow of air through a material sample where the differential pressure created across the material under study is accurately measured. In the old version of the international standard [8], ISO described another procedure, called method $\mathrm{B}$, where the airflow is alternated. In this case, it is necessary to determine the alternate component of the pressure 
produced by an oscillating piston in a volume that is occupied by the sample. However, implementation of these standardized procedures requires a rather complex and unusual instrumentation, and it is also necessary to measure sound pressures at a very low frequency. In addition, to avoid the effects of turbulent flow in the pores of the material, the measurement of pressure drop at extremely small airflow velocities is necessary. These facts have led to the development and use of a number of alternative methods to measure airflow resistivity [9-18]. A discussion of these alternative methods can be found in [19]. It seems that method B may well be described in the future as Part 2 of the ISO standard.

Garai and Pompoli [20] carried out an intercomparing of the ISO standard with ten different laboratories, where, in some cases, they used a nonstandardized acoustic method based on the work of Stinson and Daigle [9]. They concluded that reproducibility between laboratories should be improved, so corrections to the standard were proposed. In addition, it was confirmed that the acoustic method gives results similar to the standardized method with reasonable repeatability.

Dragonetti et al. [18] presented one of the more recent alternative methods for measuring airflow resistivity. They proposed an approach based on the complex ratio of the sound pressures measured with microphones located inside two cavities that are coupled through a conventional loudspeaker. They showed that the airflow resistance of a porous material sample can be determined from the imaginary part of the sound pressure complex ratio. From a practical viewpoint, their method is quite simple to implement and does not present the low frequency limitation, unlike the ISO alternated flow method. A comparison between experimental results using the ISO standard and the alternative methods offered by Ingard and Dear [10] and Dragonetti et al. [18] has also been presented [19]. 
In the following sections of this paper, a straightforward electroacoustic procedure based on the device by Dragonetti et al. for measuring the airflow resistivity is presented. The airflow resistivity is indirectly estimated from the total electric impedance measured at the loudspeaker connection terminals. In this method, the use of microphones is not necessary. The theoretical fundamentals are introduced in Section 2, and the details of the built measuring device are presented in Section 3. Results of the experimental validation of the method are discussed in Section 4. Finally, the main conclusions are summarized in Section 5.

\section{Theory}

\subsection{Acoustic method}

The device proposed by Dragonetti et al. [18] consists of two cavities with a square cross section that are separated by a conventional loudspeaker. Air leakage between both cavities is avoided by providing proper sealing. A material sample holder with a wire mesh at its bottom is placed on top of the upper cavity. The height of the upper and lower cavities are chosen so they behave as an acoustic compliance for frequencies as high as possible. The theory of their method also considers that the dimensions of the cavities are small compared to the wavelength. The sound pressures inside each volume are simultaneously measured by individual microphones mounted flush into the walls of the upper and lower cavities. For additional details, the reader is directed to the original paper [18]. Basically, in the case of low frequencies, the airflow resistivity $\sigma$ of a porous sample placed in the sample holder can easily be determined from the imaginary part of the complex transfer function $H=p_{u p} / p_{d w}$, where $p_{u p}$ and $p_{d w}$ are the sound pressures measured simultaneously inside the upper and lower cavities, re- 
spectively. In particular, after correction of both phase and amplitude mismatch between the microphones,

$$
\sigma=\frac{\operatorname{Im}\{H\} S}{-\omega C_{d w} d},
$$

where $\omega=2 \pi f$ is the circular frequency, $d$ is the sample thickness, $C_{d w}$ is the acoustic compliance of the lower cavity given by

$$
C_{d w}=\frac{V_{d w}}{\gamma P_{0}},
$$

$V_{d w}$ is the compressible air volume in the lower cavity, $\gamma$ is the specific heat ratio (approximately 1.41 for air), $P_{0}$ is the atmospheric pressure, and $S$ is the crosssectional area of the porous material sample.

\subsection{Electroacoustic method}

In this work, a modification of the device described above is proposed. From now on, the problem is analyzed using the theory of an electroacoustic enclosure. Let us consider a device identical to the one presented by Dragonetti et al. [18], but in which the perforations used to flush mount the microphones are eliminated. In this way, the system becomes a closed-box loudspeaker having a sealed backing volume $V_{d w}$ that is coupled with a Helmholtz resonator formed by a volume $V_{u p}$ and an aperture, usually called the port, which is the area where the material sample is placed. A sketch of the system is illustrated in Fig. 1a. This configuration consisting of a closed-box loudspeaker whose diaphragm's front is loaded with a Helmholtz resonator is known as a fourth-order symmetrical band-pass loudspeaker system. This system has been used frequently in home theaters, subwoofers, and computer loudspeaker systems, and its theory has been presented in several articles [21-23]. 


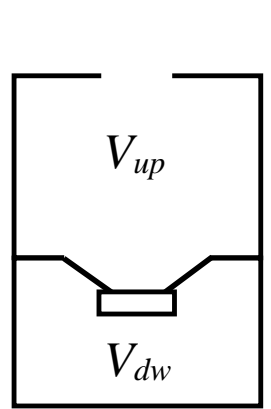

a)

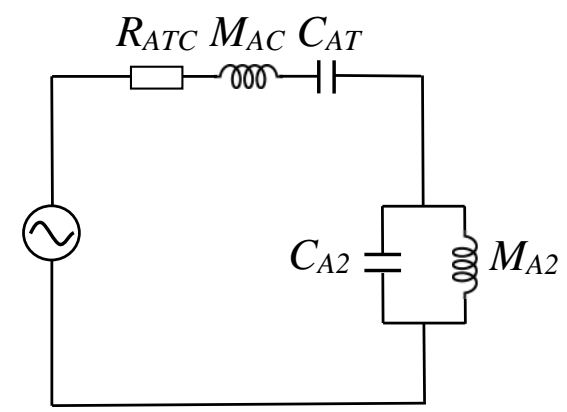

b)

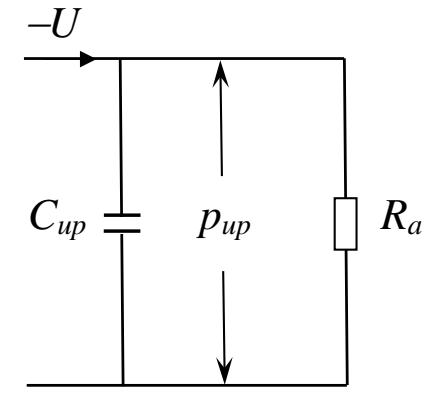

c)

Figure 1: Electroacoustic method. a) Closed-box loudspeaker loaded with a Helmholtz resonator; b) Equivalent electrical circuit of the device shown in a) [23]; c) Equivalent electrical circuit of the upper part of the device shown in a) [18].

Figure 1b shows the acoustical analogous circuit when the front enclosure is ported, and the rear enclosure is sealed [23]. In this circuit, $M_{A 2}$ is the acoustic mass of front enclosure port or vent, including air load, $C_{A T}$ considers the total acoustic compliance of loudspeaker and rear enclosure $\left(C_{d w}\right)$, and $R_{A T C}$ represents the total acoustic resistance of the closed box and loudspeaker. Figure 1c shows the analogous circuit corresponding to the upper part of the system devised by Dragonetti et al. [18] when a material sample is placed on top of the upper cavity. By comparing Figs. $1 \mathrm{~b}$ and $1 \mathrm{c}$, it can be noted that $C_{u p}$ corresponds to $C_{A 2}$ and that $M_{A 2}$ is equivalent to an acoustic surface impedance $Z_{a}$, which depends on both the material sample and the acoustic load on the outer face of the material looking toward the free air $\left(Z_{r a d}\right)$. This $Z_{a}$ is referred to flow acoustic impedance in the work by Dragonetti et al. [18].

On the other hand, the total electric impedance of the system, $Z_{E T}$, is given 
by [21-23]

$$
Z_{E T}=Z_{E}+\frac{(B l)^{2}}{Z_{A T} S_{D}^{2}},
$$

where $Z_{E}=R_{E}+j \omega L_{E}$ is the pure electric impedance of the loudspeaker, where $R_{E}$ is the electric resistance (dc) of the voice coil and $L_{E}$ is the voice-coil inductance, $S_{D}$ is the cross-sectional area of the sample holder, $B l$ is the electromagnetic coupling constant (the effective induction of loudspeaker magnet times the effective length of voice coil in magnetic gap), and $Z_{A T}$ is the total acoustic impedance of the system (see Fig. 1b) given by

$$
Z_{A T}=R_{A T C}+j \omega M_{A C}-j \frac{1}{\omega C_{A T}}+Z_{2}
$$

where the impedance $Z_{2}$ includes the effect of the acoustic compliance of the upper volume, $C_{u p}$, and the specific acoustic load impedance, $Z_{a}$. For the unloaded case (i.e., without the sample material), we have that

$$
Z_{2}=\frac{Z_{\text {rad }}}{1+j \omega C_{u p} Z_{r a d}}
$$

with $Z_{\text {rad }}$ being the acoustic radiation impedance, which can be approximated at low frequencies $(k a<0.5)$ as $[18]$

$$
Z_{r a d}=\frac{\rho_{0} c}{S_{D}}\left[(k a / 2)^{2}+j 0.6 k a\right]
$$

where $c$ is the speed of sound, $k=\omega / c$ is the free-field wave number in the air, and $a$ is the equivalent radius of the open end surface $S_{D}$. For the loaded case (i.e., with the sample material in place), according to the assumptions made in [18] in which $Z_{\text {rad }}$ can be neglected for low frequencies, we have

$$
Z_{2}=\frac{Z_{a} / S_{D}}{1+j \omega C_{u p} Z_{a} / S D}
$$


At low frequencies, according to the model of sound propagation in air-saturated porous materials having a rigid frame, $Z_{a}$ can be approximated as $[1,18]$

$$
Z_{a}=R_{a}+j \omega d\left(M_{a}+M_{k}\right)=\sigma d+j \omega d\left(M_{a}+M_{k}\right)
$$

where $R_{a}=\sigma d$ is the airflow resistance, $d$ is the material thickness, $M_{a}=\rho_{0} \alpha_{\infty} / \phi$, $\rho_{0}$ is the static air mass density, $\alpha_{\infty}$ is the tortuosity, and $\phi$ is the porosity, and $M_{k}=2 M_{a} \alpha_{\infty} \eta / \sigma \phi \Lambda^{2}$, where $\eta$ is the dynamic viscosity of air and $\Lambda$ is the viscous characteristic length. Therefore, substituting Eq. (8) into Eq. (7) and expressing $Z_{2}=R_{2}+j X_{2}$ gives

$$
R_{2}=\frac{R_{A}}{\omega^{4}\left(C_{u p} M_{A}\right)^{2}+\omega^{2}\left(\left(C_{u p} R_{A}\right)^{2}-2 C_{u p} M_{A}\right)+1},
$$

and

$$
X_{2}=\frac{-\omega\left[C_{u p} M_{A}^{2} \omega^{2}-M_{A}+C_{u p} R_{A}^{2}\right]}{\omega^{4}\left(C_{u p} M_{A}\right)^{2}+\omega^{2}\left(\left(C_{u p} R_{A}\right)^{2}-2 C_{u p} M_{A}\right)+1},
$$

where $R_{A}=R_{a} / S_{D}$ and $M_{A}=d\left(M_{a}+M_{k}\right) / S_{D}$.

\subsection{Determining the airflow resistance and reactance}

The proposed approach for obtaining the airflow resistivity is based on the search of the first maximum of the electric impedance curve (i.e., when the imaginary part is zero). Therefore, if $f_{1}$ is the frequency at which the first maximum occurs, from Eq. (3) the total electric impedance becomes

$$
\left.Z_{E T}\right|_{f=f_{1}}=R_{E}+\frac{(B l)^{2}}{R_{A T} S_{D}^{2}}
$$

where $R_{A T}=R_{A T C}+R_{2}$, where $R_{2}$ equals the radiation resistance $R_{\text {rad }}$ when there is no material in the sample holder. 


\subsubsection{Calibration}

For determining the airflow resistivity through the proposed method, a calibration procedure is essential. First, in addition to knowing the values of $R_{E}$ and $B l$, a measure of the total electric impedance of the system without the material sample is required. The value of $R_{E}$ can be determined directly from the impedance curve when the frequency approaches zero (dc). The value of $B l$ can either be given by the loudspeaker's manufacturer or measured using classical techniques [24]. Once the total electrical impedance without the sample is measured as a function of frequency, we obtain the frequency $f_{1}$ at which the first maximum is located to determine $R_{A T}$. $R_{A T}$ is assumed as $R_{A T C}$ for the calibration of the system and allows one to obtain $R_{2}$ after the system is calibrated. Therefore, using Eqs. (4), (9), and (10), we have the following two simultaneous equations at $f=f_{1}$

$$
\left.R_{2}\right|_{f=f_{1}}=\frac{R_{A}}{\omega_{1}^{4}\left(C_{u p} M_{A}\right)^{2}+\omega_{1}^{2}\left(\left(C_{u p} R_{A}\right)^{2}-2 C_{u p} M_{A}\right)+1}
$$

$$
\omega_{1} M_{A C}-\frac{1}{\omega_{1} C_{A T}}-\frac{\omega_{1}\left[C_{u p} M_{A}^{2} \omega_{1}^{2}-M_{A}+C_{u p} R_{A}^{2}\right]}{\omega_{1}^{4}\left(C_{u p} M_{A}\right)^{2}+\omega_{1}^{2}\left(\left(C_{u p} R_{A}\right)^{2}-2 C_{u p} M_{A}\right)+1} .
$$

The system of Eqs. (12) and (13) is solved for $R_{A}$ and $M_{A}$ to obtain

$$
R_{A}=\frac{C_{A T}^{2} R_{2}}{\left(C_{A T} C_{u p} M_{A C}\right)^{2} \omega_{1}^{4}+\left(C_{A T} C_{u p} R_{2}^{2}-2 C_{A T} M_{A C}-2 C_{u p} M_{A C}\right) C_{A T} C_{u p} \omega_{1}^{2}+\left(C_{A T}+C_{u p}\right)^{2}},
$$

$M_{A}=\frac{1}{\omega_{1}^{2}} \frac{\left.\left(C_{A T}^{2} C_{u p} M_{A C}^{2}\right) \omega_{1}^{4}+\left(C_{u p} C_{A T} R_{2}^{2}-M_{A C} C_{A T}-2 C_{u p} M_{A C}\right) C_{A T} \omega_{A C}^{2}\right)^{2} \omega_{1}^{4}+\left(C_{A T} C_{u p} R_{2}^{2}-2 C_{A T} M_{A C}-2 C_{u p} M_{A C}\right) C_{A T} C_{u p} \omega_{1}^{2}+\left(C_{A T}+C_{u p}\right)^{2}}{.}$

154 It can be seen that we need the values of $M_{A C}$ and $C_{A T}$. To obtain these values, we may perform a calibration consisting of two steps: 1) a measurement of 
the electric impedance without the upper volume $V_{u p}$ with the original backing volume $V_{d w}$ and 2) a second measurement of electric impedance after adding a known upper volume $V$ [25]. In the first case, we measure a resonance frequency $f_{0}$ given by

$$
f_{0}=\frac{1}{2 \pi \sqrt{M_{A C} C_{A T}}},
$$

where $C_{A T}=C_{A S} \times C_{d w} /\left(C_{A S}+C_{d w}\right), C_{A S}$ is the acoustic compliance of the loudspeaker and $C_{d w}=V_{d w} / \gamma P_{0}$ [see Eq. (2)]. In the case with a known volume $V$ in place, we measure a second resonance frequency $f_{0}^{\prime}$ given by

$$
f_{0}^{\prime}=\frac{1}{2 \pi \sqrt{M_{A C} C_{A T}^{\prime}}},
$$

where $C_{A T}^{\prime}=C_{A S} \times C_{d w}^{\prime} /\left(C_{A S}+C_{d w}^{\prime}\right)$ and $C_{d w}^{\prime}=\left(V+V_{d w}\right) / \gamma P_{0}$. Dividing Eq. (16) by Eq. (17) and solving for $C_{A S}$, we get

$$
C_{A S}=C_{d w} C_{d w}^{\prime} \frac{1-\left(f_{0} / f_{0}^{\prime}\right)^{2}}{C_{d w}\left(f_{0} / f_{0}^{\prime}\right)^{2}-C_{d w}^{\prime}} .
$$

Now, using Eq. (18), we can easily determine the values of $C_{A T}$ and $M_{A C}$. Subsequently, the values of $R_{A}$ and $M_{A}$ are calculated using Eqs. (14) and (15). Finally, the airflow resistivity of the material is directly determined from $R_{A}$.

\section{Measuring device}

To implement the theory described in the previous section, a modification of a device previously built by the authors [19] was performed. The device is shown in Fig. 2. It was made of $20 \mathrm{~mm}$ thick polymethylmethacrylate (PMMA) panels. The measured volume of the upper and lower cavities is $V_{u p}=2.3 \times 10^{-3} \mathrm{~m}^{3}$ and $V_{d w}=9.9 \times 10^{-4} \mathrm{~m}^{3}$, respectively. The upper part of the device is composed by a perforated grate where the material sample is held. The perforated area of the 
sample holder is $64.7 \%$. Both cavities are coupled through a 3-inch-wide loudspeaker (Fonestar UT-354), which has a good response in the range of frequencies used in this study. Appropriate seal of each part of the device was secured to avoid air leaks that introduce large errors.

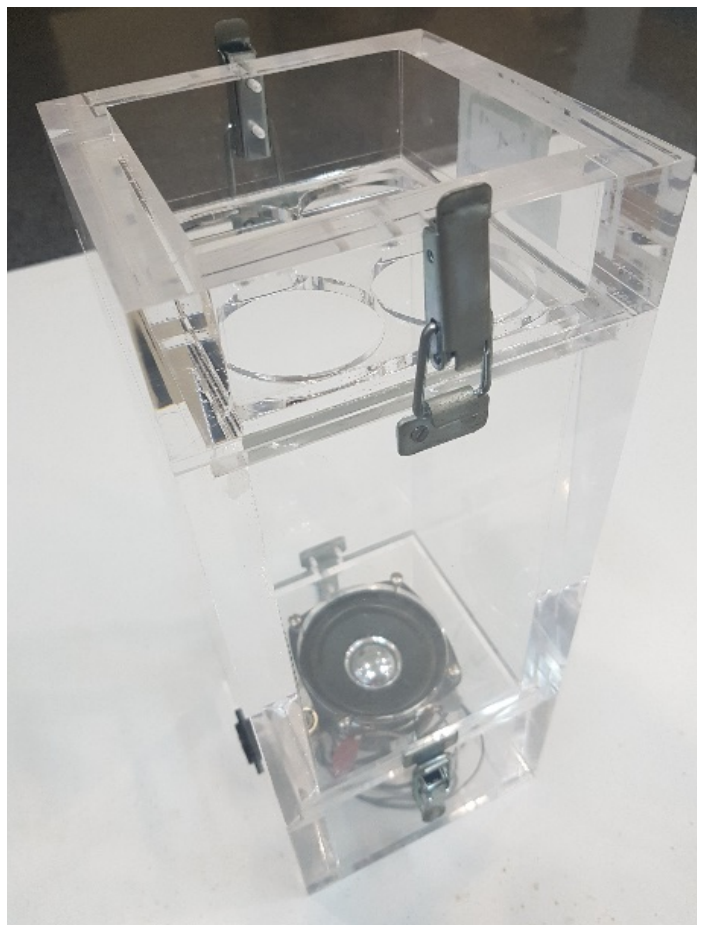

Figure 2: Photograph of the constructed measuring device.

The measurement of the total electric impedance was made using a $100 \mathrm{ohms}$ reference resistor connected in series between the signal generator and the loudspeaker connection terminals. The results were obtained using the software LIMP from ARTA software [26] running in a personal computer. A swept sine excitation signal with a frequency range of $5-2000 \mathrm{~Hz}$ was used to drive the measuring device. Both impedance phase and magnitude were calculated by measuring the 
voltage across the resistor and across the loudspeaker connection terminals of the measuring device. The equations derived in this paper were implemented into MATLAB computer codes to calculate the results.

\section{Experimental results}

The calibration process described in Section 2.3.1 was performed in the built device. A frequency $f_{0}=187.8 \mathrm{~Hz}$ was determined from the corresponding peak at resonance in the electric impedance amplitude curve measured without the upper cavity. A known volume $V=2.37 \times 10^{-3} \mathrm{~m}^{3}$ was added to the upper part of the measuring device, and the new measured resonance frequency was $f_{0}^{\prime}=156.11 \mathrm{~Hz}$. The results are shown in Fig. 3. Using both resonance frequencies and considering that $C_{d w}=7.02 \times 10^{-9} \mathrm{~m}^{5} / \mathrm{N}$ and $P_{0}=10^{5} \mathrm{~N} / \mathrm{m}^{2}$, we obtain that $C_{A S}=5.5 \times 10^{-9} \mathrm{~m}^{5} / \mathrm{N}$ and $M_{A C}=232.6 \mathrm{~kg} / \mathrm{m}^{4}$.

Figure 4 shows the measurement of the total electrical impedance (amplitude and phase angle) when the device is open and when a $19 \mathrm{~mm}$ thick sample of sound-absorbing material made of coco fiber is placed in the sample holder. Without the sample, the characteristic behavior of a fourth-order symmetrical bandpass loudspeaker system is noticed. We see two peaks in the curve of impedance magnitude, the first around $175 \mathrm{~Hz}$, which is related to the resonance of the rear enclosure (when the imaginary part is zero), and the second one at $306 \mathrm{~Hz}$ due to the front enclosure port. The effect in the impedance curve of placing a porous material in the device can also be observed. The shape of the electrical impedance curve still looks like a fourth-order band-pass loudspeaker system, but the first peak frequency is shifted down, and the maximum value of the impedance magnitude is attenuated due to the acoustical resistance provided by the material. In 


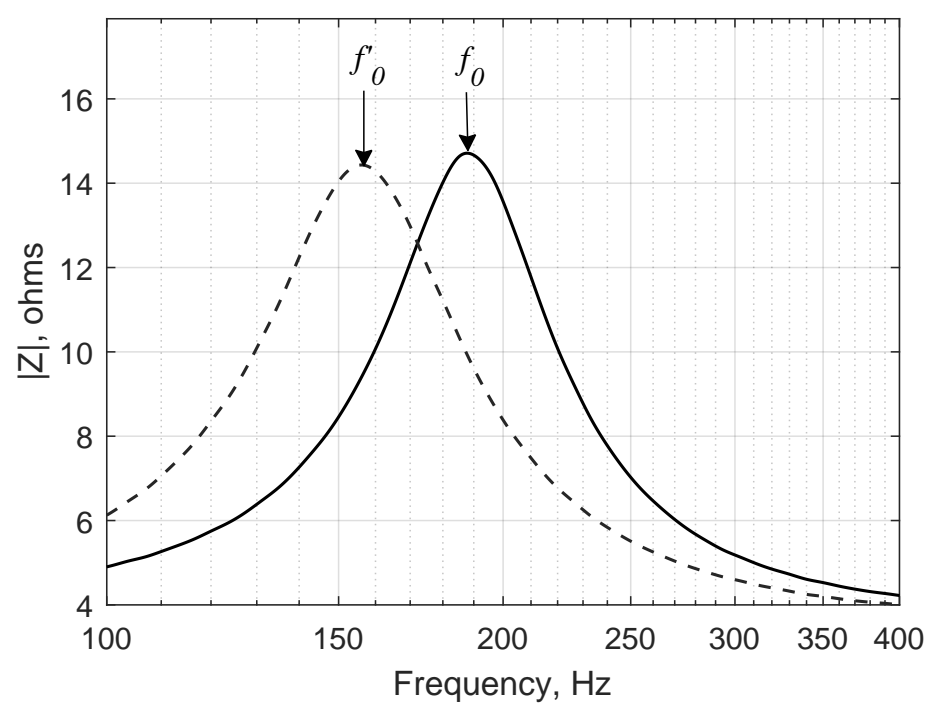

Figure 3: Measured electric impedance of the built device without the upper cavity (solid line) and with a known volume in the upper cavity (dashed line).

addition, the phase angle does not reach zero at the frequency of the second peak as it does without the sample.

Notice that when the system is unloaded, the measuring device has a first peak at a frequency of $175.06 \mathrm{~Hz}$. Therefore, the assumption made by Dragonetti et al. [18] that the contribution of $Z_{r a d}$ in Eq. (7) can be neglected for low frequencies is plausible in this case because $k a=0.14$, which is less than 0.5 .

To assess the proposed method, six samples of porous sound-absorbing materials were considered. Three of them are made of recycled polyester fibers, and the others are made of natural coconut fibers. All of these materials have been previously studied by the authors of this paper [19,27]. Table 1 presents the experimental results and some nonacoustical parameters. For the unloaded system (without a material sample), the measured values of the first peak frequency 

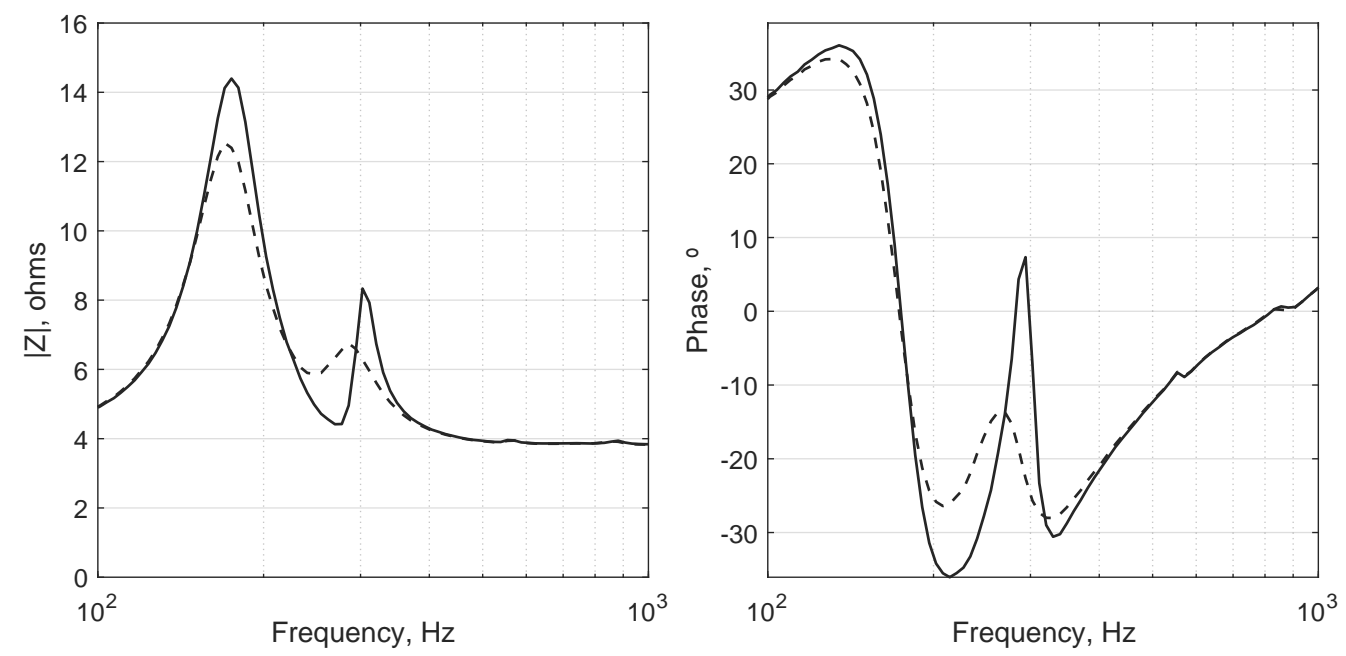

Figure 4: Results of the measured electrical impedance of the device without the material sample (solid line) and loaded with a $19 \mathrm{~mm}$ thick material made of coco fiber (dashed line).

and the maximum amplitude of the magnitude of the electrical impedance were $175.1 \mathrm{~Hz}$ and $14.4 \mathrm{ohms}$, respectively. The last two columns of Table 1 report the comparison of the values of the airflow resistivity determined with the proposed method with those obtained through the ISO standard method [8]. A fairly good agreement between the results obtained by the two methods can be observed. It is worth noticing that the samples used in the built measuring device had a square area, while circular samples were employed in the standardized method. As noticed by Dragonetti et al. [18], although each pair of compared samples is cut from the same panel, using exactly the same sample for both methods would be better. This is particularly evident when measuring materials made of either recycled or natural fibers.

It was also observed that the electroacoustic method works reasonably well for 
Table 1: Experimental results of airflow resistivity performed by the proposed electroacoustic method and a standardized method for different porous materials.

\begin{tabular}{cccccccccc}
\hline & & & & & & Airflow & \multicolumn{2}{c}{$\sigma, \mathrm{Ns} / \mathrm{m}^{4}$} \\
\cline { 8 - 10 } Material & Density, & Thickness, & $f_{1}$, & $|Z|$ & $R_{A}$, & resistance, & ISO & Proposed \\
& $\mathrm{kg} / \mathrm{m}^{3}$ & $\mathrm{~mm}$ & $\mathrm{~Hz}$ & $\mathrm{ohms}$ & $\mathrm{Ns} / \mathrm{m}^{5}$ & $\mathrm{Ns} / \mathrm{m}^{3}$ & 9053 & method \\
\hline Coco1 & 128.0 & 19 & 171.4 & 10.32 & 4689 & 46.9 & 2600 & 2468 \\
Coco2 & 100.0 & 29 & 171.8 & 10.63 & 4243 & 42.4 & 1900 & 1463 \\
CocoS3 & 83.0 & 42 & 170.1 & 10.20 & 4581 & 45.8 & 1200 & 1091 \\
$\mathrm{I} 400-40$ & 10.0 & 40 & 173.7 & 11.41 & 3411 & 34.1 & 1100 & 853 \\
$\mathrm{I} 400-30$ & 14.0 & 30 & 173.5 & 10.74 & 4462 & 44.6 & 1500 & 1487 \\
$\mathrm{I} 600-30$ & 25.0 & 33 & 174.5 & 9.28 & 7970 & 79.7 & 2400 & 2415 \\
\hline
\end{tabular}

values of low airflow resistance. For materials having low airflow resistance (i.e., low values of the acoustic resistance $R_{A}$ ), the electrical impedance curve clearly shows the second peak in frequency, which is associated with the port effect. The amplitude of this peak decreases as the airflow resistance increases, up to a point in which this peak cannot be distinguished, although the first main peak still remains. An example of this effect is shown in Fig. 5 where the experimental results for two material samples made of high-density recycled foam are reported. These materials, designated as D60 and D180, have been studied as sound-absorbing materials in earlier works by the authors $[19,27]$. Foam D60 has density of 61 $\mathrm{kg} / \mathrm{m}^{3}$, thickness of $32 \mathrm{~mm}$, and standardized measured airflow resistance of 195.2 $\mathrm{Ns} / \mathrm{m}^{3}$. Foam D180 has density of $211 \mathrm{~kg} / \mathrm{m}^{3}$, thickness of $33 \mathrm{~mm}$, and airflow resistance of $4092 \mathrm{Ns} / \mathrm{m}^{3}$. It is observed that the fourth-order band-pass behavior disappears, and the upper cavity becomes a closed box due to the absence of sound 
radiation through the port. Under these conditions, some calculated parameters are physically inconsistent, and the estimated airflow resistivity values using the proposed approach are unreliable. It means that materials that provide a very high acoustic resistance to the system cannot be measured with this method because not enough sound transmission is possible through the material (i.e., the airflow resistivity may be high, but the equivalent airflow resistance is not). Further tests have revealed that the limit value of acoustic resistance in the present built measuring device is around $10 \mathrm{kNs} / \mathrm{m}^{5}$, which corresponds to an airflow resistance of $100 \mathrm{Ns} / \mathrm{m}^{3}$, approximately.

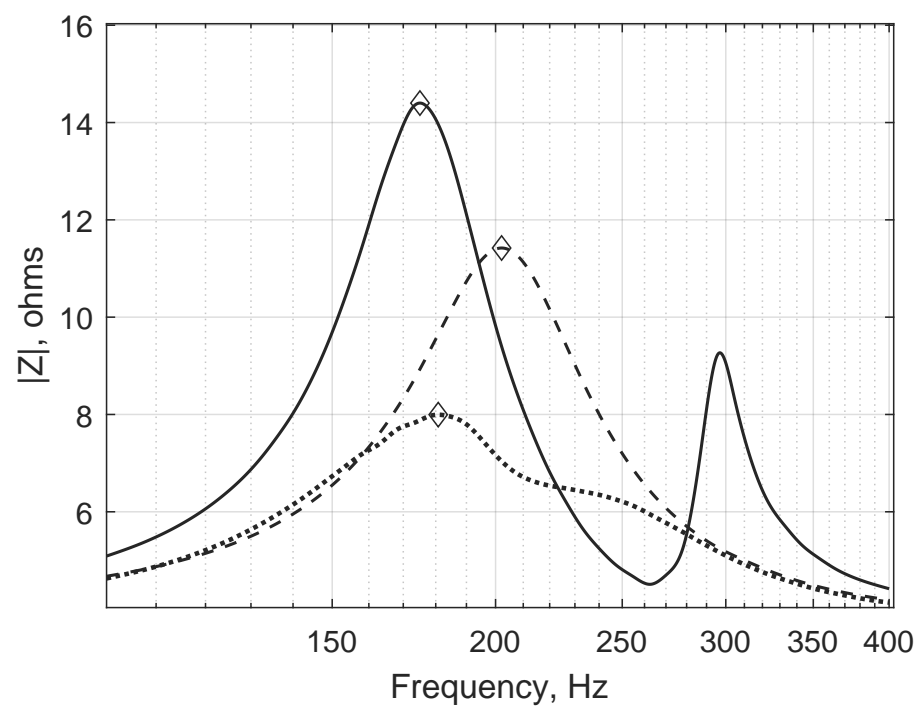

Figure 5: Results of the measured electrical impedance of the device without the material sample (solid line) and loaded with two high-density materials made of recycled polyurethane foam: D60, $\sigma=6.1 \mathrm{kNs} / \mathrm{m}^{4}$ (dotted line) and $\mathrm{D} 180, \sigma=124 \mathrm{kNs} / \mathrm{m}^{4}$ (dashed line). The diamonds indicate the frequencies at which the first maximum impedance magnitude is observed. 


\section{Conclusions}

An electroacoustic method for indirectly measuring the airflow resistivity of porous materials has been presented. Its practical implementation does not need the use of microphones, which makes the method simple and inexpensive. After a straightforward calibration, the airflow resistance is obtained from the measurement of the total electric impedance of the device. Although the experiments were carried out using a specialized software for loudspeaker impedance measurement, simpler instrumentation could be used for the same purpose.

We observed that the results obtained with the present method agree well with those obtained through a standardized method. However, the method makes sense while the measuring device behaves as a fourth-order band-pass loudspeaker system. This occurs as long as the acoustic resistance provided by the material under test is not too high, which results in an upper limit of the measurable airflow resistance. In the measuring device built in this study, this upper limit for the airflow resistance was found to be approximately $100 \mathrm{Ns} / \mathrm{m}^{3}$.

The measuring device can be particularly useful in measuring airflow resistivity of thin textile sample materials, such as those studied in [3-5], because their values of specific airflow resistance are usually low, although when dividing these values by a very small thickness, a high airflow resistivity is obtained.

In summary, it is concluded that the proposed electroacoustic method described in this paper could be another viable alternative, or a useful complement, to existing standardized methods. 


\section{References}

[1] Allard JF, Atalla N. Propagation of sound in porous media: modelling sound absorbing materials. 2nd ed. Chichester: Wiley; 2009.

[2] Bies DA, Hansen $\mathrm{CH}$. Flow resistance information for acoustical design. Appl Acoust 1980;13:357-391. https://doi.org/10.1016/0003$682 \times(80) 90002-x$

[3] Jaouen L, Becot FX. Acoustical characterization of perforated facings. J Acoust Soc Am 2011;129:1400-1406. https://doi.org/10.1121/1.3552887

[4] Pieren R. Sound absorption modeling of thin woven fabrics backed by an air cavity. Textile Res J 2012;82:864-874. https://doi.org/10.1177/0040517511429604

[5] Tang X, Jeong CH, Yan X. Prediction of sound absorption based on specific airflow resistance and air permeability of textiles. J Acoust Soc Am 2018;144:EL100-EL104. https://doi.org/10.1121/1.5049708

[6] ISO 9053-1. Acoustics - Materials for acoustical applications - Part 1: Static airflow method. Geneva: International Standardization Organization; 2018. 
[7] ASTM C522-03. Standard test method for airflow resistance of acoustical materials. West Conshohocken, PA: ASTM International; 2016. https://doi.org/10.1520/c0522

[8] ISO 9053. Acoustics - Materials for acoustical applications - Determination of airflow resistance. Geneva: International Standardization Organization; 1991.

[9] Stinson MR, Daigle GA. Electronic system for the measurement of flow resistance, J Acoust Soc Am 1983;83:2422-2428. https://doi.org/10.1121/1.396321

[10] Ingard KU, Dear TA. Measurement of acoustic flow resistance, J Sound Vib 1985;103:567-572. https://doi.org/10.1016/s0022-460x(85)80024-9

[11] Woodcock R, Hodgson M. Acoustic methods for determining the effective flow resistivity of fibrous materials. J Sound Vib 1992;153:186-191. https://doi.org/10.1016/0022-460x(92)90639-f

[12] Ren M, Jacobsen F. A method of measuring the dynamic flow resistance and reactance of porous materials. Appl Acoust 1993;39:265-276. https://doi.org/10.1016/0003-682x(93)90010-4

[13] Picard MA, Solana P, Urchueguia JF. A method of measuring the dynamic flow resistance and the acoustic measurement of the effective static flow resistance in stratified rockwool samples, J Sound Vib 1998;216:495-505. https://doi.org/10.1006/jsvi.1998.1725

[14] Panneton R, Olny X. Acoustical determination of the parameters governing 
viscous dissipation in porous media, J Acoust Soc Am 2006;119:2027-2040. https://doi.org/10.1121/1.2169923

[15] Sebaa N, Fellah ZEA, Fellah M, Lauriks W, Depollier C. Measuring flow resistivity of porous material via acoustic reflected waves, J Appl Phys 2005;98:084901. https://doi.org/10.1063/1.2099510

[16] Fellah ZEA, Fellah M, Sebaa N, Lauriks W, Depollier C. Measuring flow resistivity of porous materials at low frequencies range via acoustic transmitted waves. J Acoust Soc Am 2006;119:1926-1928. https://doi.org/10.1121/1.2179749

[17] Doutres O, Salissou Y, Atalla N, Panneton R. Evaluation of the acoustic and non-acoustic properties of sound absorbing materials using a three-microphone impedance tube, Appl Acoust 2010;71:506-509. https://doi.org/10.1016/j.apacoust.2010.01.007

[18] Dragonetti R, Ianniello C, Romano AR. Measurement of the resistivity of porous materials with an alternating air-flow method, J Acoust Soc Am 2011;129:753-764. https://doi.org/10.1121/1.3523433

[19] del Rey R, Alba J, Arenas JP, Ramis J. Evaluation of two alternative procedures for measuring airflow resistance of sound absorbing materials. Arch Acoust 2013;38:547-554. https://doi.org/10.2478/aoa-2013-0064

[20] Garai M, Pompoli F. A European inter-laboratory test of airflow resistivity measurements. Acta Acust united Acust 2003;89:471-478.

[21] Geddes ER. An introduction to band-pass loudspeaker systems. J Audio Eng Soc 1989;37:308-342. 
[22] Berkhoff AP. Impedance analysis of subwoofer systems. J Audio Eng Soc 1994;42:4-14.

[23] Matusiak GP, Dobrucki AB. Fourth-order symmetrical band-pass loudspeaker systems. J Audio Eng Soc 2002;50:4-18.

[24] Beranek LL. Acoustics. 2nd ed. New York: Acoustical Society of America; 1986.

[25] Arenas JP, Darmendrail L. Measuring sound absorption properties of porous materials using a calibrated volume velocity source. Meas Sc Tech 2013;24:105005. https://doi.org/10.1088/0957-0233/24/10/105005

[26] Mateljan I. LIMP: Program for loudspeaker impedance measurement, User Manual (ver 1.9.0); 2017.

[27] del Rey R, Alba J, Arenas JP, Sanchis VJ. An empirical modelling of porous sound absorbing materials made of recycled foam. Appl Acoust 2012;73:604-609. https://doi.org/10.1016/j.apacoust.2011.12.009 